\title{
A New Technique for the Surgical Treatment of Atlantoaxial Instability: C1 Lateral Mass and C2-3 Transfacet Screwing
}

\author{
Salim SENTURK, Goktug AKYOLDAS, Onur YAMAN, Ali Fahir OZER \\ Koc University Hospital, Department of Neurosurgery, Istanbul, Turkey
}

\section{ABSTRACT}

Atlantoaxial instability is a special entity that may be caused by many disorders such as trauma, tumor, arthritis, congenital malformation and infection. Atlantoaxial fixation is needed to provide stability, prevent neurological deficits and correct deformity. The aim of this report is to introduce an alternative technique for the treatment of atlantoaxial instability in patients who have vertebral artery anomaly, anomalous C2 or osteoporosis. C1-2-3 fixation was performed in a 50-year-old male patient with atlantoaxial instability due to os odontoideum. C1 lateral masses were identified and screw placement was performed. C2 facet joints were identified bilaterally. The superior margin of the junction of pedicle and the lamina was used as the entry point and $3.5 \times 22 \mathrm{~mm}$ screws were inserted from C2 facet joint to the C3 facet joint in the mediolateral and craniocaudal direction under fluoroscopic guidance with caution. The posterior fixation screws were interconnected with two rods. Finally, autologous grafts were placed posterolaterally to encourage the fusion. The patient's complaints were relieved after the surgery. C1-C2 instability was not seen in the postoperative radiological examinations. In the surgical treatment of $\mathrm{C} 1-2$ instability, our technique could help reduce the possibility of vertebral artery injury in patients who have a vertebral artery course anomaly or when it is difficult to place C2 pedicle screws due to anomalous $\mathrm{C} 2$ pedicles and osteoporosis. High fusion rate could be achieved with this technique due to passing through the four cortical surfaces. No wire or allograft was required. Thus, the instrumentation cost could be reduced.

KEYWORDS: Atlantoaxial instability, Fixation, Surgical technique

\section{INTRODUCTION}

$\Lambda$ tlantoaxial instability is a special entity that may be caused by many disorders such as trauma, tumor, arthritis, congenital malformation and infection $(3,12,13)$. Many surgical procedures have been described for treatment of C1-2 instability. Gallie and Brooks-Jenkins introduced traditional posterior wiring techniques that carried a neurological deficit risk and required postoperative external orthosis $(1,2)$. The surgical technique of atlantoaxial transarticular screw fixation which was introduced by Magerl and Seemann have provided enough stability and a high fusion rate without the need for prolonged external stabilization (8). The development of C1 lateral mass and C2 transpedicular screw fixation have been commonly performed instead of transarticular screws. However, placement of the transpedicular screw carries a similar risk of vertebral artery (VA) injury with clinical series presenting $2-8 \%$ incidence of VA injury (7). Wright et al. described a new technique. In this technique, crossing screws placed directly into the lamina of C2 has been used for atlantoaxial fixation (15). Nevertheless, the biomechanical studies showed that crossing intralaminar screws did not provide stability as strong as transarticular screws during lateral bending and axial rotation motions (4). Furthermore, this technique carries the risk of screw breakout into the spinal canal $(6,14)$. In some cases, C1-2 instrumentation is not possible due to anatomical limitations. Some surgeons prefer to use a C1-2-3 construct with different procedures (4). In this perspective, C1-2-3 construct was performed for the treatment of C1-2 instability in a 50-yearold male patient with os odontoideum. 
Senturk S. et al: New Technique for Atlantoaxial Instability

The objective of this report is to introduce a new technique for the treatment of C1-2 instability in patients with anomalous C2, poor bone quality, or atypical VA course.

\section{CASE PRESENTATION}

A 50-year-old male patient with the complaints of neck and right arm pain, upper and lower extremity numbness and weakness was admitted to our clinic. Mild (grade 4/5) quadriparesis, bilaterally increased deep tendon reflexes and positive Hoffmann sign were noted during the neurological examination. The computed tomography (CT) scan showed os odontoideum and the magnetic resonance scan showed severe stenosis and myelomalacia in the craniocervical region and these were correlated with patient's complaints (Figure 1A, B). We performed posterior decompression of occiput and C1, and fusion due to the clinical and radiological findings. After the surgery, his symptoms resolved and he was discharged on day 2. On the sixth month and first year follow-up, no complications were detected (Figure 2A, B).

\section{SURGICAL TECHNIQUE}

The patient was positioned prone on the operation table. The head was fixed with the Mayfield three-pin holder. After a midline incision from the occiput to the $\mathrm{C} 4$ spinous process, the cervical spine was exposed from skull to C3. Once the decompression of occiput and $\mathrm{C} 1$ could be performed to decompress the occiput and spinal canal if necessary, then bilateral C1 lateral masses were identified and placement of lateral mass screws was performed under fluoroscopic guidance. Bilateral C2 pedicle diameters were thin on the preoperative CT scan (Figure 3) and low bone quality of C2 was observed during the peroperative assessment. Therefore,
C2 facet joints were identified bilaterally and the superior margin of the junction of pedicle and the lamina was used as the entry point and $3.5 \times 22 \mathrm{~mm}$ screws were inserted from the $\mathrm{C} 2$ facet joint to the $\mathrm{C} 3$ facet joint in the medial-lateral and craniocaudal direction under fluoroscopic guidance with caution to provide rigid fixation and avoid VA injury. The screws were interconnected with two standard rods. Finally, autologous grafts getting from decompression of occiput and $\mathrm{C} 1$ were placed posterolaterally to encourage the fusion (Figure 4A, B).

\section{- DISCUSSION}

The atlantoaxial joint has a unique functional and structural characteristic compared with the remainder of the whole spine in anatomical and biomechanical aspects. Ultimately, the instability across the atlantoaxial joint may cause risk of myelopathy and sudden death. Atlantoaxial fixation is needed to provide stability, prevent neurological deficits and correct deformity. Many surgical procedures have been described, but in some cases, placement of the instrumentation is not possible.

Variants of VA course increase the risks related to placement of C2 screw. Placement of the C1-2 transarticular and C2 pedicle screws cannot be possible in $18 \%$ of patients due to an atypical course of VA (10). The standard C1-2 screw fixation procedure may also not be feasible in patients who are obese or who have a cervical kyphotic deformity. Furthermore, fixation of the C1-2 construct can be quite challenging due to congenital anomalies such as os odontoideum and hypoplastic C2 pedicles. In our study, the patient had os odontoideum anomaly and also thin $\mathrm{C} 2$ pedicle. In their study, Sairyo et al. concluded that the minimum C2 lamina diameter for safe
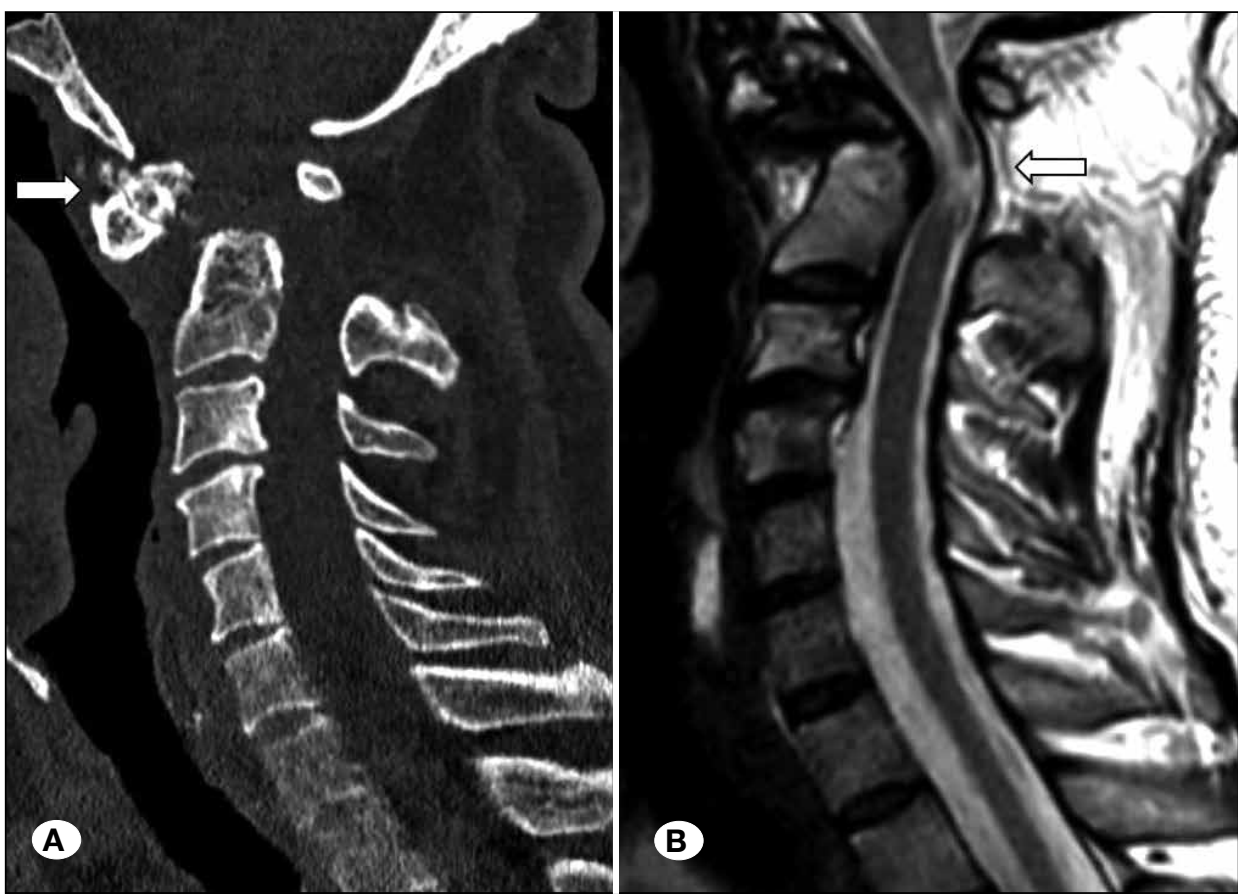

Figure 1: A) Preoperative sagittal CT scan of os odontoideum (white arrow), B) preoperative sagittal T2weighted MRI scan. 

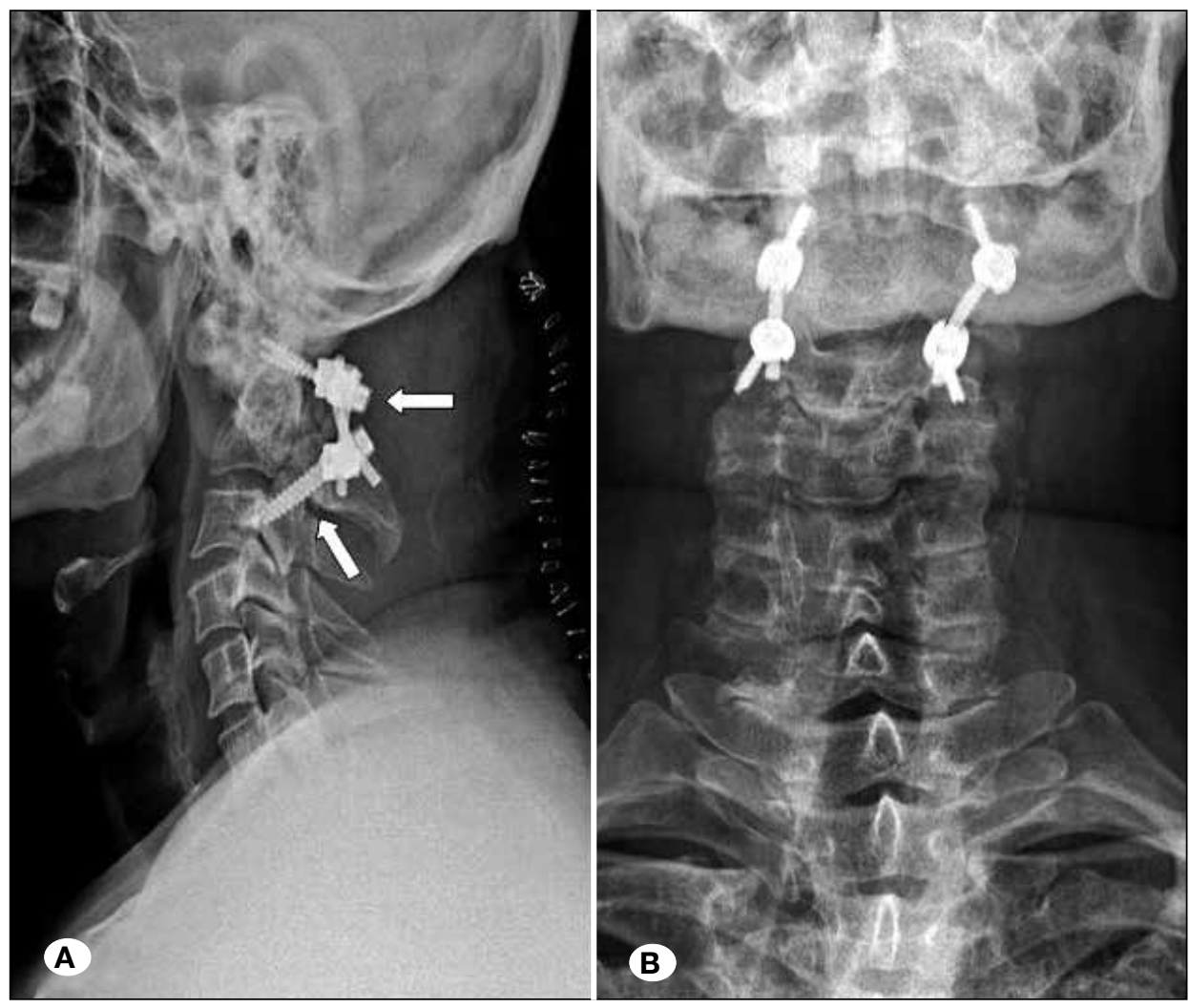

Figure 2: A) Postoperative lateral radiography (Upper white arrow shows $\mathrm{C} 1$ lateral mass screws, lower arrow shows C2-3 transfacet screws), B) anteroposterior $(A-P)$ view.

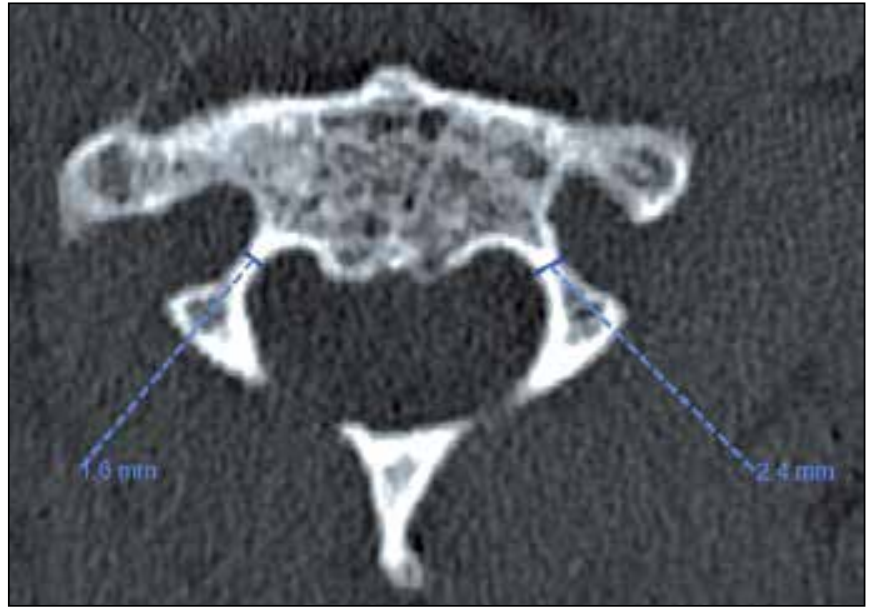

Figure 3: C2 pedicle diameters - $2.4 \mathrm{~mm}$ on the left and $1.6 \mathrm{~mm}$ on the right.

implantations of C2 pedicle screws should be $3.5 \mathrm{~mm}$ (11). Moreover, Meng and Xu's radiographic study of C2 anatomy in patients with os odontoideum recommended at least 5.5 $\mathrm{mm}$ diameter (9). Additionally, Meng and Xu showed 50\% of patients with os odontoideum have C2 pedicle diameters less than $3.5 \mathrm{~mm}(9)$. In this study, our patient's $\mathrm{C} 2$ pedicle diameters were $2.4 \mathrm{~mm}$ on the left and $1.6 \mathrm{~mm}$ on the right. Because of the thin C2 lamina and poor bone quality, the fusion was extended to C3. Our technique is straightforward and can be used independently of the C-2 anatomy.

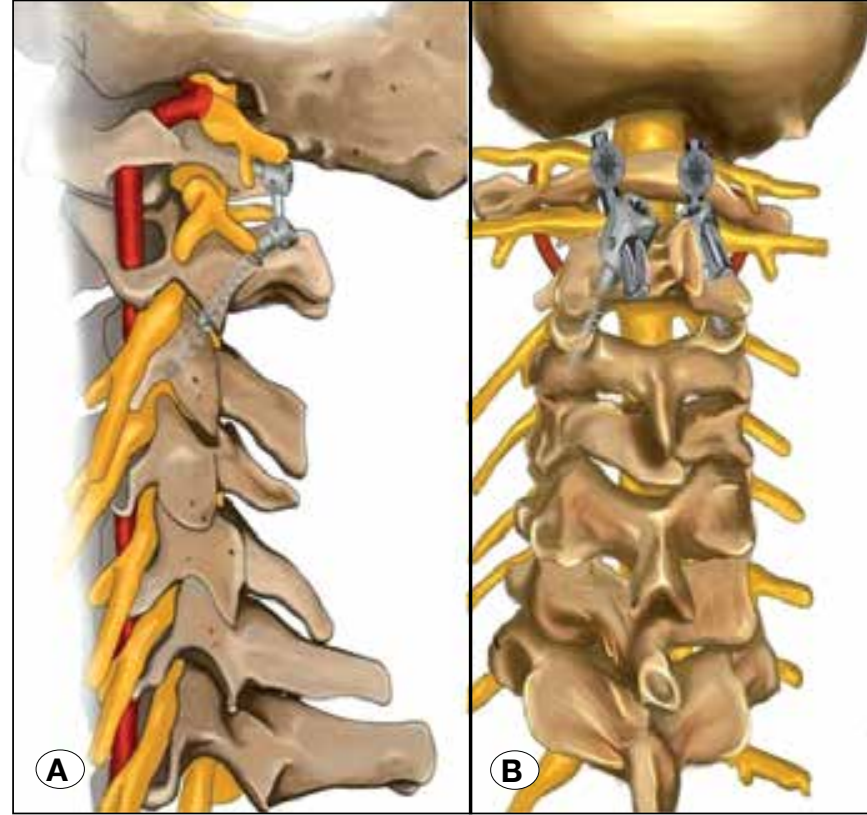

Figure 4: A) Illustration of the technique (lateral), B) illustration of the technique (A-P view).

Stronger fixation and increased pull-out strength can be provided by this technique because the screws pass through the four cortical surfaces. This technique could also help reduce the risk of $V A$ injury in patients who have a high course of VA. Moreover, no wires and sublaminar graft are required for 
this procedure. The autologous graft getting from occiput and C1 decompression could be placed posterolateral to the rods.

The most important drawback of our technique is the obvious need to incorporate an intact level in the fixation. Hartl et al. compared biomechanics of $\mathrm{C} 1-2$ fixation ( $\mathrm{C} 1$ lateral mass $+\mathrm{C} 2$ pedicle screw) and $\mathrm{C} 1-3$ fixation (C1-C3 lateral mass and sublaminar wiring of C2) (4). They concluded that C1-3 fixation significantly decreased the range of motion (ROM) at the $\mathrm{C} 1-2$ segment during all motions relative to normal. Compared with C1-2 fixation, there was remarkably more ROM with $\mathrm{C} 1-3$ fixation during flexion and axial rotation and there was no significant difference between other motion patterns (10).

Low bone quality is the one of the major causes for fusion failure in a patient with C1-2 fixation. In 2006, Horn et al. concluded that in patients with osteoporosis, the construct might have to be extended to $\mathrm{C} 4$ to provide strong fusion (5). Additionally, they reported $100 \%$ fusion rate in 7 patients with adequate mean follow-up (13.1 months). In this perspective, we believe that the loss of normal C2-3 motion is a minor consequence compared with potential catastrophic complications associated with an injury to the VA and fusion failure. Therefore, C1-2-3 fixation was performed with an alternative technique.

\section{CONCLUSION}

In the surgical treatment of $\mathrm{C} 1-2$ instability, our alternative technique could help reduce the possibility of VA injury in patients who have a VA course anomaly, or when it is difficult to place $\mathrm{C} 2$ pedicle screws due to anomalous C2 pedicle and osteoporosis. High fusion rate could be achieved with this technique due to passing through the four cortical surfaces. No wire or allograft is required. Thus, the instrumentation cost could be reduced.

\section{- REFERENCES}

1. Brooks AL, Jenkins EB: Atlantoaxial arthrodesis by the wedge compression method. J Bone Jt Surg Am 60(3): 279-284, 1978

2. Gallie WE: Fractures and dislocation of the upper cervical spine. Am J Surg 46: 495-499, 1939

3. Gautschi OP, Payer M, Corniola MV, Smoll NR, Schaller $\mathrm{K}$, Tessitore E: Clinically relevant complications related to posterior atlanto-axial fixation in atlanto-axial instability and their management. Clin Neurol Neurosurg 123: 131-135, 2014
4. Hartl R, Chamberlain RH, Fifield MS, Chou D, Sonntag VK, Crawford NR: Biomechanical comparison of two new atlantoaxial fixation techniques with $\mathrm{C} 1-2$ transarticular screw-graft fixation. J Neurosurg Spine 5: 336-342, 2006

5. Horn EM, Hott JS, Porter RW, Theodore N, Papadopoulos SM, Sonntag VK: Atlantoaxial stabilization with the use of C1-3 lateral mass screw fixation. Technical note. J Neurosurg Spine 5: 172-177, 2006

6. Lehman RA Jr, Sasso RC, Helgeson MD, Dmitriev AE, Gill NW, Rosner MR, Riew KD: Accuracy of intraoperative plain radiographs to detect violations of intralaminar screws placed into the C2 vertebrae. Spine 32: 3036-3040, 2007

7. Ma W, Feng L, Xu R, Liu X, Lee AH, Sun S, Zhao L, Hu Y, Liu G: Clinical application of $\mathrm{C} 2$ laminar screw technique. Eur Spine J 19: 1312-1317, 2010

8. Magerl F, Seemann P: Stable posterior fusion of the atlas and axis by transarticular screw fixation. In: Kehr P, Weidner A (eds), Cervical spine I. New York:Springer, 1987:322-327

9. Meng XZ, Xu JX: The options of C2 fixation for os odontoideum: A radiographic study for the $\mathrm{C} 2$ pedicle and lamina anatomy. Eur Spine J 20: 1921-1927, 2011

10. Paramore CG, Dickman CA, Sonntag VK: The anatomical suitability of the C1-2 complex for transarticular screw fixation. J Neurosurg 85: 221-224, 1996

11. Sairyo K, Sakai T, Higashino K, Tamura T, Katoh S, Yasui $\mathrm{N}$ : Cervical and upper thoracic screwing for spinal fusion: Strategy for its safe insertion to avoid major complications. Arch Ortho Trauma Surg 129: 1447-1452, 2009

12. Shuhui G, Jiagang L, Haifeng C, Hao ZB, Qing HS: Surgical management of adult reducible atlantoaxial dislocation, basilar invagination and Chiari malformation with syringomyelia. Turk Neurosurg 26(4): 615-621, 2016

13. Tessitore E, Bartoli A, Schaller K, Payer M: Accuracy of freehand fluoroscopy-guided placement of $\mathrm{C} 1$ lateral mass and $\mathrm{C} 2$ isthmic screws in atlanto-axial instability. Acta Neurochir (Wien) 153 : 1417-1425; discussion 1425, 2011

14. Wang MY: Cervical crossing laminar screws: Early clinical results and complications. Neurosurgery 61:ONS311-ONS316, 2007

15. Wright NM: Posterior C2 fixation using bilateral, crossing C2 laminar screws: Case series and technical note. J Spinal Disord Tech. 17: 158-162, 2004 